\title{
Furfural production from xylose and birch hydrolysate liquor in a biphasic system and techno-economic analysis
}

\author{
Gerardo Gómez Millán ${ }^{1,2} \cdot$ Rahul Prasad Bangalore Ashok $^{3} \cdot$ Pekka Oinas $^{3} \cdot$ Jordi Llorca $^{2} \cdot$ Herbert Sixta $^{1}$
}

Received: 9 October 2019 / Revised: 12 March 2020 / Accepted: 18 March 2020 / Published online: 8 April 2020

(C) The Author(s) 2020

\begin{abstract}
Furfural has been highlighted as one of the top ten most rewarding bio-based building blocks by the US Department of Energy. In this study, furfural was produced from xylose and birch hydrolysate liquor employing a batch reactor in a biphasic system. The formation of furfural was conducted under auto-catalyzed conditions. 2-sec-Butylphenol was used as extractant to promptly extract furfural from the aqueous phase in order to minimize furfural degradation reactions. The effect of time, temperature, and organic-to-aqueous phase ratio were investigated. The maximum furfural yields from xylose and birch hydrolysate liquor as feedstock under auto-catalyzed conditions when employing 2-sec-butylphenol (SBP) were $59 \mathrm{~mol} \%$ and $54 \mathrm{~mol} \%$, respectively. In the monophasic system when using hydrolysate, $46 \%$ furfural was yielded. Based on a techno-economic analysis carried out for furfural, the total investment cost for a plant integrated with an existing pulp mill or bio-refinery is estimated as $14 \mathrm{M} €$. The minimum selling price of furfural found to be $1.62 € \mathrm{~kg}^{-1}$. With a furfural selling price of $1.93 € \mathrm{~kg}^{-1}$, the payback period is approximately 5 years and an internal rate of return (IRR) of $20.7 \%$ is achieved at the end of the project lifetime.
\end{abstract}

Keywords Furfural $\cdot$ Birch hydrolysate liquor $\cdot 2$-sec-Butylphenol $\cdot$ Xylose $\cdot$ Bio-refinery $\cdot$ Techno-economic analysis

Gerardo Gómez Millán and Rahul Prasad Bangalore Ashok contributed equally to this work

Electronic supplementary material The online version of this article (https://doi.org/10.1007/s13399-020-00702-4) contains supplementary material, which is available to authorized users.

Gerardo Gómez Millán gerardo.gomezmillan@aalto.fi

Herbert Sixta

herbert.sixta@aalto.fi

1 Department of Bioproducts and Biosystems, School of Chemical Engineering, Aalto University, P.O. Box 16300, FI-00076 Espoo, Finland

2 Department of Chemical Engineering, Institute of Energy Technologies and Barcelona Research Center in Multiscale Science and Engineering, Universitat Politècnica de Catalunya, Eduard Maristany 10-14, 08019 Barcelona, Spain

3 Department of Chemical and Metallurgical Engineering, School of Chemical Engineering, Aalto University, P.O. Box 16100, FI-00076 Espoo, Finland

\section{Introduction}

Bioeconomy is significantly influencing markets worldwide; therefore, new alternative pathways which shape sustainable development and manage natural resources have to be created in the future. In Finland, bioeconomy models based in forestry processes are noted particularly as the new direction towards a thriving green economy $[1,2]$. So far, the competitiveness of pulp and paper mills is struggling as a result of digitalization of literature and global increasing capacities especially in equatorial and sub-equatorial countries with larger tree growing quotas and low-cost labor that sets severe economic strain on the producers in temperate latitudes like the Nordics [3]. This ongoing trend can give a new potential to existing forest companies to also develop as significant bio-based chemical and biofuel producers, in addition to cellulose-based products. This position urges to transform their mass production of paper-grade pulp en route to other products with smaller production quantity but larger gross margin, such as methane gas from wastewater [4]; bio-oil from lignin [5]; and value-added chemicals like furfural (FUR), hydroxymethylfurfural (HMF), and acetic acid from hydrolysate liquor from dissolving pulp [6]. An attractive sugar contained in high amounts, xylose, has not yet been fully utilized in the paper and pulp industry, which is mixed with lignin- 
derived compounds and burned to provide process heat [7]. Currently, the Nordic oil company St1 Oy produces FUR, lignin, and turpentine as by-products in their Cellulonix ${ }^{\circledR}$ process that aims to form ethanol from saw dust [8].

The current market price of FUR is fluctuating between 800 and $1600 € / t$ [9]. It is expected that the global FUR market grows from 380 to 615 million $€^{1}$ by 2026 [10]. Nevertheless, process technologies in industrial scale produce around 50\% FUR yield through Quaker Oats technology. Besides, the process is accompanied by environmental concerns including toxic effluents and high energy consumption. China still continues to produce over $70 \%$ of the total FUR market volume, followed by Dominican Republic and South Africa. Among the more than 80 chemicals that can be produced directly or indirectly from FUR, furfuryl alcohol is the largest application segment market (accounting approximately $85 \%$ of the total FUR market in 2013) with application in the escalating biofuel and food sectors [11]. Other attractive platform molecules obtained from FUR are furan-2,5-dicarboxylic acid and methyltetrahydrofuran.

In order to boost the current FUR yield and tackle current process challenges, recent advances to replace mineral acids $\left(\mathrm{H}_{2} \mathrm{SO}_{4}\right.$ and $\left.\mathrm{HCl}\right)$ with solid acids and ionic liquids have been undertaken by academia and industry $[6,12,13]$. Yemiş and Mazza [14] studied the conversion of xylose and xylan into FUR employing three strong mineral acids (hydrochloric acid, sulfuric acid, and nitric acid) and three weak acids (phosphoric acid, acetic acid, and formic acid). In that paper, hydrochloric acid and phosphoric acid were found to be the most effective catalysts as strong mineral acid and as weak acid, respectively. Furthermore, organic acids such as formic, oxalic, fumaric, and maleic acids have demonstrated being a good alternative to dehydrate sugars into furanics [15-17]. Especially, oxalic acid has shown good catalytic activity to form FUR from xylose. Hongisiri et al. [17] reported comparable FUR yields when employing oxalic acid and $\mathrm{HCl}$.

Various studies have been proposed to avert the production of humins and consequently heighten the FUR yield. An effective approach is to immediately extract FUR from the aqueous phase using an organic solvent. The key considerations to identify a suitable solvent for a biphasic system including FUR extraction are good chemical stability, high boiling point (higher than that of FUR), no azeotrope formation with FUR, mutual solubility of solvent and water should be minimal, and the FUR partition coefficient should be as high as possible [18-20]. Moreover, avoidance of modifiers (salts such as $\mathrm{NaCl}$ ) is preferred [21]. Salts increase the partition coefficient, but in doing so, corrosion of the reactor and viable deactivation of active sites on solid acid catalysts are created [21, 22]. Ethyl acetate was first used as extracting media by Trimble

\footnotetext{
${ }^{1}$ Original prices reported in USD were converted to EU with a conversion rate of $1 \mathrm{USD}=0.91362 €$ on September 30, 2019.
}

and Dunlop [23]. Subsequent investigation incorporated studies on diverse organic solvents, e.g., 2-methoxy-4propylphenol [20], 1-butanol [24], cyclo pentyl methylether (CPME) [25-27], cyclohexanol [28], methyl isobutyl ketone (MIBK) [28, 29], 2-methyltetrahydrofuran (MTHF) [30, 31], and widely-used toluene [28]. A lignin-derived organic solvent, 2-sec-butylphenol [19], offers high partition coefficient for FUR in organic-aqueous systems [20]. Additionally, due to its water-immiscibility nature, it does not require phase modifiers and it has a higher boiling point $\left(227^{\circ} \mathrm{C}\right)$ compared to that of FUR $\left(162{ }^{\circ} \mathrm{C}\right)$, which allows for its recovery in higher purity as a top product in a distillation step $[20,30]$. The additional separation step adds cost to the process. Therefore, the organic layer must be recovered and reused to design the process economically viable [32].

Therefore, we hereby compare the formation of FUR from xylose (used as model compound) and the pentosane fraction present in the birch hydrolysate liquor under auto-catalyzed conditions. We focus on the formation of FUR from xylose and birch hydrolysate liquor using 2-sec-butylphenol as organic solvent. Furthermore, it is necessary to develop an economical and energy efficient process that can produce a concentrated product with a low-cost production and a minimum usage of reagents. In the present study, the solvents are recovered for reuse in the process.

\section{Experimental}

\subsection{Materials}

2-sec-Butylphenol (97.5\%) was purchased from SigmaAldrich and was used in the experiments without further purification. D-Xylose powder (99\%), formic acid (98\%), levulinic acid (99\%), acetic acid (99\%), furfural (98\%), and hydroxymethylfurfural (99\%) were purchased from SigmaAldrich and used for the preparation of calibration standards for HPLC analysis. A Synergy ${ }^{\circledR}$ Merck Millipore device was used to achieve an ultrapure (type I) water quality grade (resistivity $18.2 \mathrm{M} \Omega \mathrm{cm}$ at $25{ }^{\circ} \mathrm{C}$ ) [33], which was used for preparing the solutions.

The birch hydrolysate was supplied by Stora Enso (Stora Enso, Imatra, Finland), which was used for the dehydration reaction experiments. The composition of the hydrolysate can be seen in Table A1 (in the Supplementary Information).

\subsection{Methods}

\subsubsection{Catalytic activity tests}

Birch hydrolysate from Stora Enso (Imatra, Finland) was filtered by using a glass filter with porosity 4 (Duran). The composition of the liquor was determined 
according to the analytical method NREL/TP-51042,623 [34]. The first set of experiments was performed with xylose in the absence of catalyst. These experiments can be considered as auto-catalyzed reaction system where some fragmentation products (namely carboxylic acids) or intermediates, formed during the hydrothermal treatment, may have a catalytic effect [35-37]. The second set of experiments was performed using the birch hydrolysate liquor.

In a typical experiment, a borosilicate glass reactor $(V=$ $10 \mathrm{~cm}^{3}$ ) was loaded with $3 \mathrm{ml}$ of a xylose solution $\left(186 \mathrm{~mol} \mathrm{~m}^{-3}\right)$ or the birch hydrolysate liquor. The xylose concentration used is similar to that found in the birch hydrolysate liquor (Table A1 in the Supplementary Information). The hydrothermal reaction includes magnetic stirring $\left(600 \mathrm{~min}^{-1}\right)$ and microwave-assisted heating $(\leq 850 \mathrm{~W}$, Monowave 300, Anton Paar GmbH, Graz, Austria). After the reaction took place, the reactor was rapidly cooled to $60{ }^{\circ} \mathrm{C}$ by utilizing compressed air. The highest temperature and the longest reaction time studied at the present work were $210^{\circ} \mathrm{C}$ and $180 \mathrm{~min}$, respectively. After the reaction occurred, the solutions were tested for FUR yield, selectivity to FUR, and xylose conversion at the reaction temperatures of 170 , 190 , and $210^{\circ} \mathrm{C}$ with different reaction times in the range of 30-180 min.

Due to the slow settling of the aqueous and organic phases, which is related to the relative similar densities $\left(d_{4}^{20}\right)$ of both water and 2-sec-butylphenol (0.982) [18], samples were centrifuged after hydrothermal reaction using a Minispin ${ }^{\circledR}$ centrifuge (Eppendorf AG, Germany) for 6 min with a rotation speed of $8000 \mathrm{rpm}$ (Fixed Angle Rotor).

\subsubsection{Determination of FUR and by-products}

The liquid samples were analyzed by high-performance liquid chromatography (HPLC) operating a Dionex Ultimate 3000 HPLC (Dionex, Sunnyvale, CA, USA) device equipped with refractive index (RI) and ultraviolet (UV) diode array detectors. Product separation was achieved on a Rezex ROA-Organic Acid $\mathrm{H}^{+}(8 \%)$ LC column $(7.8 \mathrm{~mm} \times 300 \mathrm{~mm}$, Phenomenex, USA). Aqueous sulfuric acid $\left(0.0025 \mathrm{~mol}^{-1}\right)$ was used as eluent with a flow rate of $0.5 \mathrm{ml} \mathrm{min}{ }^{-1}$. The column temperature and the RI detector temperature were set to $55^{\circ} \mathrm{C}$. The FUR concentration was determined by the UV detector at a wavelength of $280 \mathrm{~nm}$. The xylose concentration was analyzed simultaneously by the RI detector and the UV detector at $210 \mathrm{~nm}$ [38]. The samples were filtered through a $0.45-\mu \mathrm{m}$ syringe filter before the analysis.

FUR from the organic phase was analyzed by gas chromatography with a flame ionization detector (GC-FID) relative to acetone as internal standard (IS). The column used was a DBWAXetr $(30 \mathrm{~m}, 0.32 \mathrm{~mm}$ i.d., $1-\mu \mathrm{m}$ film thickness) from Agilent Technologies Inc. The injected samples $(0.5 \mu \mathrm{L})$ were subjected to a splitless ratio of 20:1 in the inlet, which was maintained at $250{ }^{\circ} \mathrm{C}$ and a pressure of 12.1 bar. Helium was used as the carrier gas. The oven was initially maintained at $80^{\circ} \mathrm{C}$ for $1 \mathrm{~min}$, after which the temperature was increased to $250{ }^{\circ} \mathrm{C}$ at a rate of $30{ }^{\circ} \mathrm{C} \mathrm{min}^{-1}$. The FID was operated at $250{ }^{\circ} \mathrm{C}$ with hydrogen, air, and helium delivered at

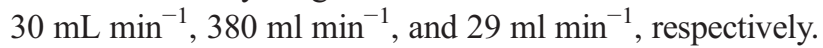

In this study conversion, selectivity to FUR and FUR yield $[12,30,39]$ were calculated according to equations 1,2 and 3 , respectively. The following equations have been used for the mathematical evaluation of the obtained results when using xylose solution $\left(186 \mathrm{~mol} \mathrm{~m}^{-3}\right)$ :

$X_{\mathrm{xyl}}=\frac{c_{\mathrm{xyl}}^{\mathrm{in}}-c_{\mathrm{xyl}}^{f}}{c_{\mathrm{xyl}}^{\mathrm{in}}} \times 100[\%]$

$Y_{\text {fur }}=\frac{c_{\text {fur }}}{c_{\text {xyl }}^{\text {in }}} \times 100[\%]$

$S_{\mathrm{xyl}}^{\mathrm{fur}}=\frac{c_{\mathrm{fur}}}{c_{\mathrm{xyl}}^{\text {in }}-c_{\mathrm{xyl}}^{f}} \times 100[\%]$

where $X$ is the conversion of xylose, $S$ is the selectivity to FUR, $Y$ is the FUR yield, and $c$ is the concentration in mol $\mathrm{m}^{-3}$ (the subscripts xyl, fur, in, $f$ refer to xylose, FUR, initial, final).

When hydrolysate liquor was used, pentose conversion, selectivity to FUR, and FUR yield were calculated equations 4,5 and 6 , respectively.

Conversion of pentoses (namely arabinose and xylose), selectivity to FUR, and FUR yield were determined in accordance with the previous section employing hydrolysate liquor as reactant.

$$
\begin{aligned}
& \mathrm{X}_{\text {Pentoses }}= \frac{c_{\text {Pentoses }}^{0}-c_{\text {Pentoses }}^{e}}{c_{\text {Pentoses }}^{0}} \times 100[\%] \\
& Y_{\text {fur }}=\frac{\left(C_{\text {FUR_ut }}^{e}-C_{\text {FUR_ut }}^{0}\right)+C_{\mathrm{FUR}}^{\text {Org }}}{C_{\text {Pentoses_t }}^{0}+C_{\text {FUR_ut }}^{0}} \times 100[\%] \\
& S_{\text {Pentoses }}^{\text {fur }}=\frac{\left(\left(C_{\text {FUR_ut }}^{e}-C_{\text {FUR_ut }}^{0}\right)+C_{\text {FUR }}^{\text {Org }}\right) \times C_{\text {Pentoses }}^{0}}{\left(C_{\text {Pentoses }}^{0}-C_{\text {Pentoses }}^{e}\right) \times\left(C_{\text {Pentoses } \_t}^{0}+C_{\text {FUR_ut }}^{0}\right)} \\
& \times 100[\%]
\end{aligned}
$$

where $X$ is the conversion of pentoses, $S$ is the selectivity to FUR, $Y$ is the FUR yield, and $c$ is the concentration in $\mathrm{mol} \mathrm{m}^{-3}$ (the subscripts and superscripts pentoses, fur, ut, t, $0, e$, Org represent: arabinose and xylose, FUR, hydrolysate liquor untreated, hydrolysate liquor treated according to the National renewable Energy Laboratory, before, after reaction, and concentration contained in the organic phase, respectively). The FUR formed initially in the birch hydrolysate has not been accounted together with the FUR produced under the experimental conditions presented in this article. 


\subsubsection{Techno-economic analysis methodology}

The process feasibility is evaluated by carrying out a technoeconomic analysis consisting of conceptual process design, mass and energy balance calculations, and total investment cost estimations. A discounted cash flow analysis is performed to determine the minimum selling price (MSP) of FUR, payback period, net present value (NPV), and internal rate of return (IRR).

The equipment mapping, sizing, and the purchased equipment cost estimation is performed using Aspen Process Economic Analyzer (Aspen Technologies, Inc., USA) based on 1st quarter 2018 pricing. A delivery allowance of $10 \%$ is applied and the delivered equipment cost is calculated using equation 7 .

Delivered equipment cost (DEC)

$$
=1.1 \text { *purchased equipment cost }
$$

The fixed capital investment is determined using equation 8. The direct and indirect costs are estimated as a fraction of the delivered equipment costs using factors from Peters et al. [40] by considering a solid-fluid processing plant. Direct costs include costs related to purchase of equipment, equipment installation, piping, electrical systems, buildings, yard improvements, and service facilities. Indirect costs account for costs arising from engineering and supervision, construction, legal expenses, and contractor fees. The contingency cost is calculated as $25 \%$ of the sum of direct and indirect costs. The OSBL (outside battery limits) cost is estimated as $20 \%$ of the total direct cost (TDC), and the working capital is taken as $10 \%$ of the fixed capital investment. Total investment is calculated following equation 9 .

Fixed capital investment (FCI)

$=$ total direct cost + total indirect cost

$$
+ \text { contingency cost }+ \text { OSBL }
$$

Total investment $=$ FCI + working capital

The annual operating cost is calculated as the sum of fixed operating costs, variable operating costs, and general expenses. The fixed operating costs account for operating labor, employee benefits, supervision, laboratory, insurance and taxes, maintenance, and plant overheads. Variable operating costs include raw material and utility costs, and are estimated based on mass and energy balances obtained from process simulation models of Aspen plus ${ }^{\circledR}$. The operating labor cost is calculated by considering 2.9 operators per shift position [40] and one supervisor. The number of shifts is taken as 5 with monthly wages of $3000 €$ and $5000 €$ for the operators and supervisor respectively. General expenses is taken as $10 \%$ of the sum of fixed and variable operating costs and accounts for costs related to administration, distribution and marketing, and research and development.

The plant is operated in continuous mode $(8000 \mathrm{~h} /$ year $)$ with a FUR production capacity of $5 \mathrm{kt} / \mathrm{year}$ and a project lifetime of 20 years with $100 \%$ equity financing. Capital expenses are incurred in year 1 of the project without any operating costs or revenues. In year 2, the working capital is invested and the plant starts operating at full capacity, thereby generating revenue. Since profit is made by the plant from year 2 onwards, depreciation can be charged and is calculated using straight-line depreciation with a 10 -year recovery period. In year 20 , the working capital is released and is accounted as positive increment to the cash flow. The parameters used in the techno-economic analysis are summarized in Table 1. The major assumptions for the techno-economic analysis are as follows:

- Since the process utilizes a pre-hydrolysate stream from the bio-refinery or pulp mill as a raw material, it is assumed that the pre-hydrolysate cost is negligible and not taken into consideration when estimating the annual operating costs.

- It is assumed that energy demand for the reactors is met by utilizing the surplus thermal energy available in the pulp mill or bio-refinery. The pulp mill supplies the thermal energy needed at a cost of $10 € / \mathrm{MWh}$ [42], and these costs are accounted for in the annual operating cost.

- Furthermore, it is assumed that the lignin removal from the pre-hydrolysate is carried out in the pulp mill or biorefinery, and costs related to this are not taken into consideration in the techno-economic analysis.

\section{Results and discussion}

\subsection{Partition coefficient of furfural}

The partition coefficient of FUR was investigated by conducting hydrothermal reactions wherein a solution of $5 \mathrm{wt} \%$ FUR in aqueous phase was heated with SBP for $30 \mathrm{~min}$ at $190^{\circ} \mathrm{C}$ at seven ratios of aqueous phase to SBP: 1:5, 1:3, 1:2, 1:1, 2:1, 3:1, and 5:1 (by volume). Fig. A1 (in the Supplementary Information) exhibits the FUR partitioning $(P)$ achieved, where $P$ was calculated using equation 10 [28].

$P=\frac{[\mathrm{FUR}]_{\mathrm{org}}}{[\mathrm{FUR}]_{\mathrm{aq}}}$

A FUR partition coefficient 36 was obtained with an aqueous-to-SBP phase ratio of $1: 5$ and $1: 3(\mathrm{v} / \mathrm{v})$. This value decreased to $28,22,19,9$, and 4 as the aqueous- 
Table 1 Parameters of techno-economic analysis [40, 41]

Techno-economic analysis parameters

\begin{tabular}{ll}
\hline Evaluation year & 2018 \\
\hline Production capacity & $5 \mathrm{kt} /$ year \\
Project lifetime & 20 years \\
Discount rate & $10 \%$ \\
Taxation & $20 \%$ \\
Contingency cost & $25 \%$ of sum of direct \\
& and indirect costs \\
Working capital & $10 \%$ of FCI \\
OSBL & $20 \%$ of TDC \\
Employee benefits & $25 \%$ of operating labor \\
Supervision & $20 \%$ of operating labor \\
Laboratory & $20 \%$ of operating labor \\
Insurance and Taxes & $3 \%$ of FCI \\
Maintenance & $3 \%$ of FCI \\
Plant overhead & $65 \%$ of sum of operating labor, \\
& supervision and maintenance \\
Operating supplies & $1 \%$ of FCI \\
General expenses & $10 \%$ of sum of fixed and variable costs \\
\hline
\end{tabular}

to-SBP fraction ratio increased to $1: 2,1: 1,2: 1,3: 1$, and $5: 1(\mathrm{v} / \mathrm{v})$. Similarly, partition coefficient decreases when the aqueous-to-organic phase ratio increases has been also observed when using 2-MTHF, CPME, and isophorone [30]. It is assumed that at high aqueous-to-organic phase ratios, the organic solvent is not able to extract FUR from the aqueous phase; thus, FUR remains in the aqueous phase where it could undergo degradation reactions.

\subsection{Effect of aqueous-to-organic phase ratio}

According to the National Center for Biotechnology Information [43], SBP is insoluble in water. However, mutual solubilities of water and SBP have been measured in a recently published paper at various temperatures from 30 to $210{ }^{\circ} \mathrm{C}$ [18]. It is observed that the mutual solubility of water and SBP used in the present paper is minimal under the given experimental conditions. Lin et al. [18] studied the mass fraction mutual solubilities for water and SBP from 303.15 to $483.15 \mathrm{~K}$ and a pressure of $2.5 \times 10^{6} \mathrm{~Pa}$. They reported that at $443.15,463.15$, and $483.15 \mathrm{~K}$, the solubility of water in SBP is $0.03,0.05$, and 0.07 , respectively; and the solubility of SBP in water at the same temperature values is $0.02,0.04$, and 0.06 .

The effect of aqueous-to-SBP phase ratio on xylose conversion and FUR formation was examined. Therefore, five ratios of aqueous-to-SBP phase (1:5, 1:2, $1: 1,2: 1,5: 1$ by volume) were proposed employing an aqueous solution containing $186 \mathrm{~mol} \mathrm{~m}^{-3}$ and SBP in biphasic systems at a temperature of $190{ }^{\circ} \mathrm{C}$ for $0.5 \mathrm{~h}$. The FUR yields obtained are presented in Fig. A2 (in the Supplementary Information) and are determined utilizing equation 2. FUR yield builds up as the aqueous-toorganic ratio increases from 1:5 up to $1: 1$ (by volume, Fig. A2). At ratios of aqueous-to-organic volumes from $2: 1$ to $5: 1$, we propose that a larger FUR yield is halted by the formation of increased degradation products. The highest FUR yield (17\%) is obtained at $190{ }^{\circ} \mathrm{C}$ in $0.5 \mathrm{~h}$ when using SBP in an aqueous-to-SBP phase ratio of 1:1 (by volume).

Selectivity to FUR and xylose conversion can be observed in Fig. A3 (in the Supplementary Information). The xylose conversion varied from 30 to $43 \%$. The selectivity to FUR increases as the aqueous-to-SBP phase ratio raises from 1:5 to $1: 2$ (by volume), from there on it declines when increasing the aqueous-to-SBP phase ratio to 5:1. A recent paper using isophorone, 2-MTHF, and
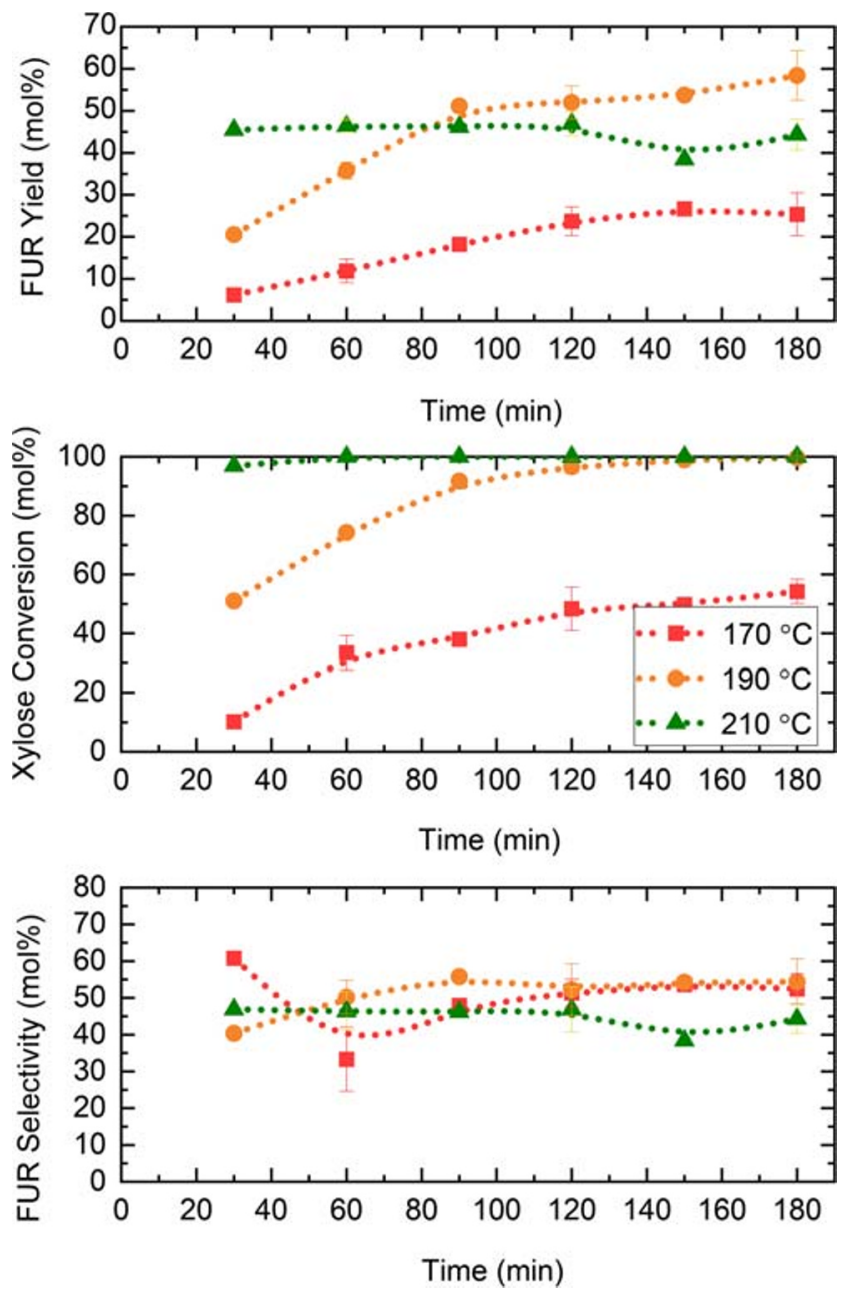

Fig. 1 Effect of reaction temperature and time on a FUR yield, $\mathbf{b}$ xylose conversion, $\mathbf{c}$ selectivity to FUR in the conversion of $186 \mathrm{~mol} \mathrm{~m}^{-3}$ xylose to FUR with an aqueous-to-SBP phase ratio of 1:1 (by volume) 
CPME corroborated similar results [30]. This could occur as a result of the saturation of the SBP to extract FUR; hence, FUR remains in the aqueous phase and degradation reactions might take place.

\subsection{Effect of reaction time and temperature in the biphasic system}

The effect of reaction time and temperature on the formation of FUR was investigated by performing reactions from 0.5 to $3 \mathrm{~h}$ at 170,190 , and $210^{\circ} \mathrm{C}$ in a biphasic system including SBP and a xylose solution of $186 \mathrm{~mol} \mathrm{~m}^{-3}$. SBP was employed as organic solvent in an aqueous-to-organic phase ratio of 1:1 (by volume). Figure 1 presents the effect of reaction time when employing SPB on FUR yield, xylose conversion, and selectivity to FUR. As it can be seen in Fig. 1b, FUR yield and xylose conversion are significantly influenced by the reaction temperature, which is in accordance with previous reports on this field [44].
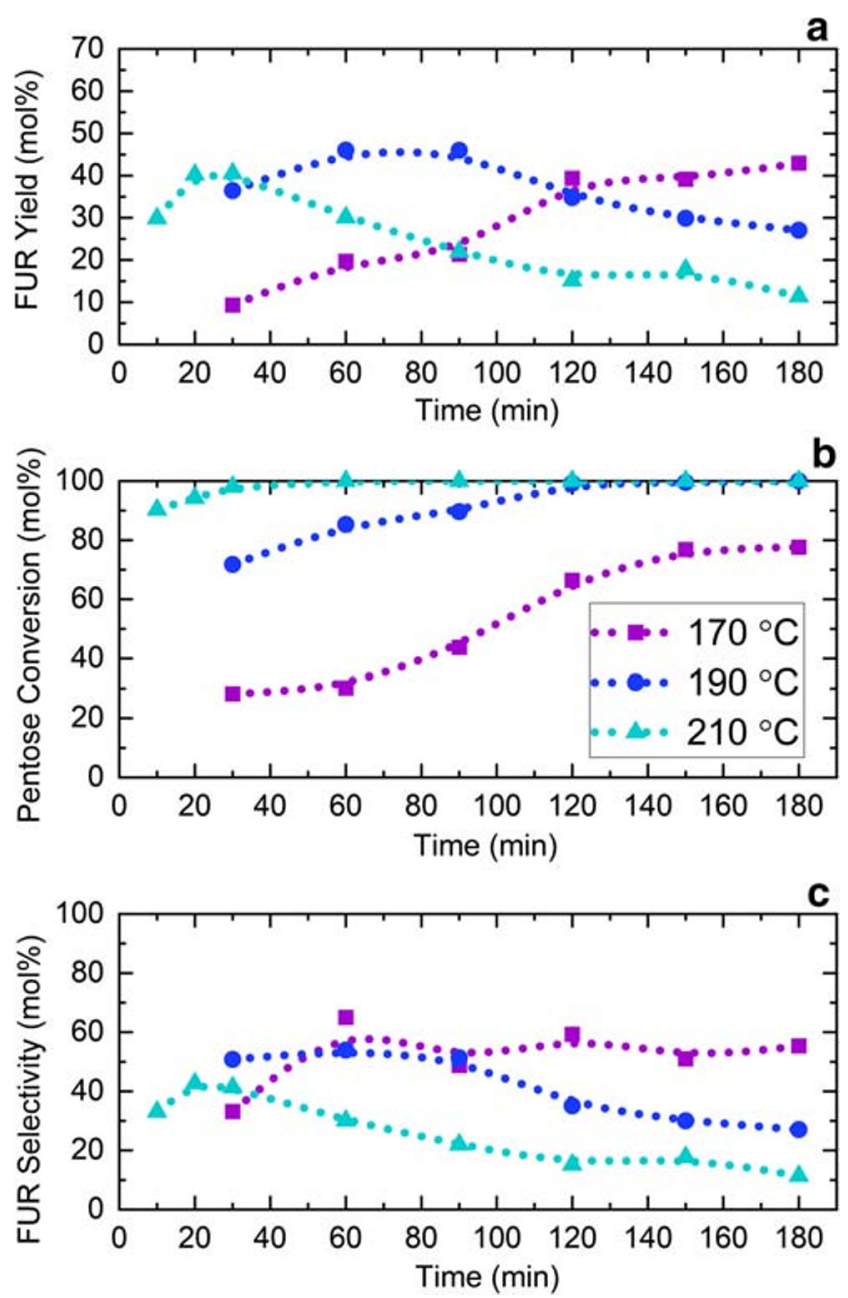

Fig. 2 Effect of temperature and reaction time on a FUR yield, $\mathbf{b}$ pentose conversion, $\mathbf{c}$ selectivity to FUR during auto-catalyzed conversion of birch hydrolysate liquor
As observed in Fig. 1a, after the first $1 \mathrm{~h}$ of the hydrothermal reaction, the FUR yield exhibited a threefold increase by raising the reaction temperature from 170 to $190{ }^{\circ} \mathrm{C}$. The highest FUR yield $(59 \%)$ was reached at $190{ }^{\circ} \mathrm{C}$ in $3 \mathrm{~h}$. The peak of the selectivity to FUR (Fig. 1c) was $60 \%, 59 \%$, and $47 \%$ at temperatures of 170,190 , and $210{ }^{\circ} \mathrm{C}$, respectively. Reaction temperature has also an effect on selectivity to FUR under these laboratory conditions as it has been observed in similar biphasic systems using cyclopentyl methyl ether (CPME), isophorone, and 2-methyltetrahydrofuran (MTHF) [30]. It can be observed that selectivity to FUR at the lowest temperature studied $\left(170{ }^{\circ} \mathrm{C}\right)$ displays the highest value in the biphasic system.

An interesting effect, that can be seen in Fig. 1a, is that at times greater than $1.5 \mathrm{~h}$, the FUR yield reached at $190{ }^{\circ} \mathrm{C}$ exceeds the FUR yield achieved at $210{ }^{\circ} \mathrm{C}$. At high reaction temperatures $\left(210^{\circ} \mathrm{C}\right)$, it is assumed that SBP no longer extracts FUR as efficiently. Hence, FUR is prone to remain in the aqueous phase rather than in SBP; therefore, degradation
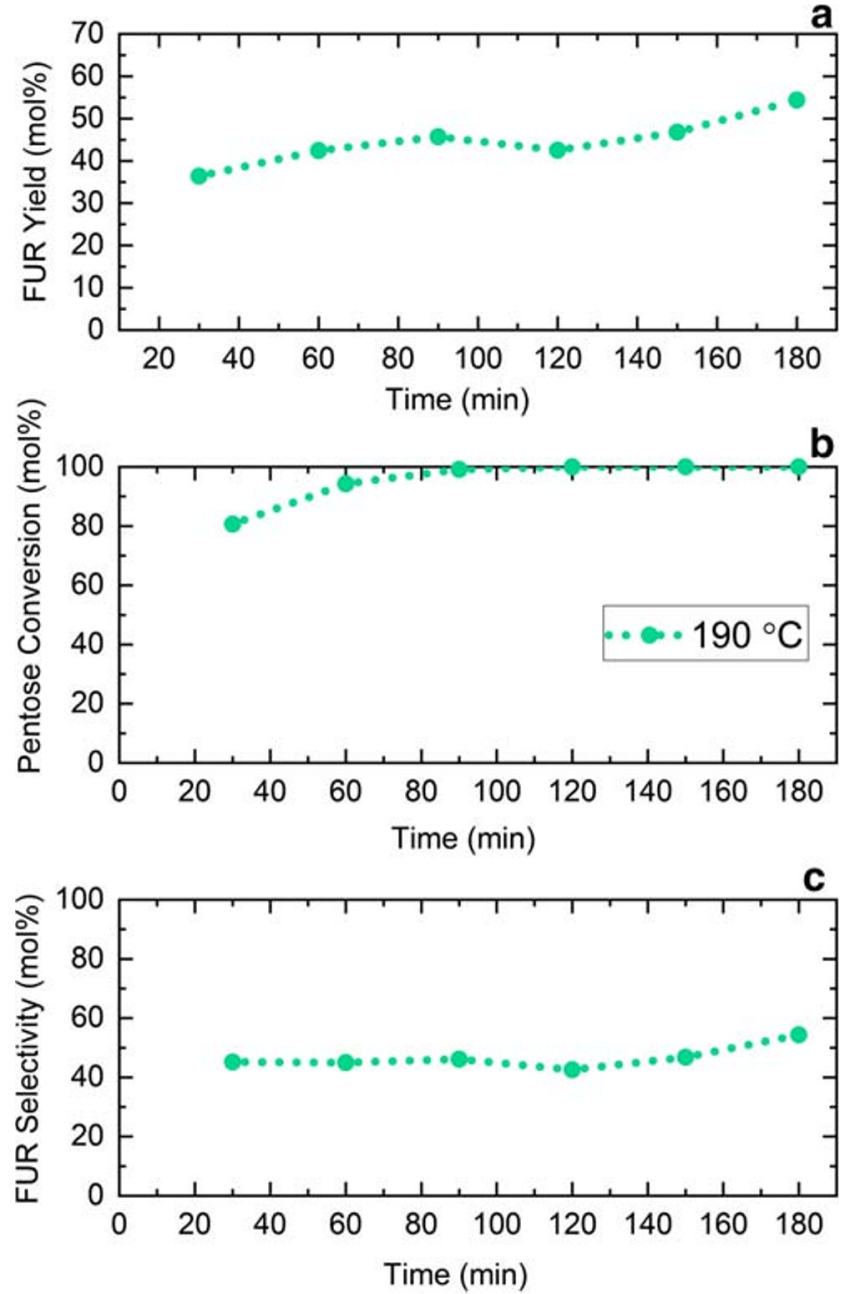

Fig. 3 a FUR yield, b pentose conversion, $\mathbf{c}$ selectivity to FUR when employing birch hydrolysate $(1.5 \mathrm{ml})$ and $\mathrm{SBP}(1.5 \mathrm{ml})$ at $190{ }^{\circ} \mathrm{C}$ under microwave irradiation 


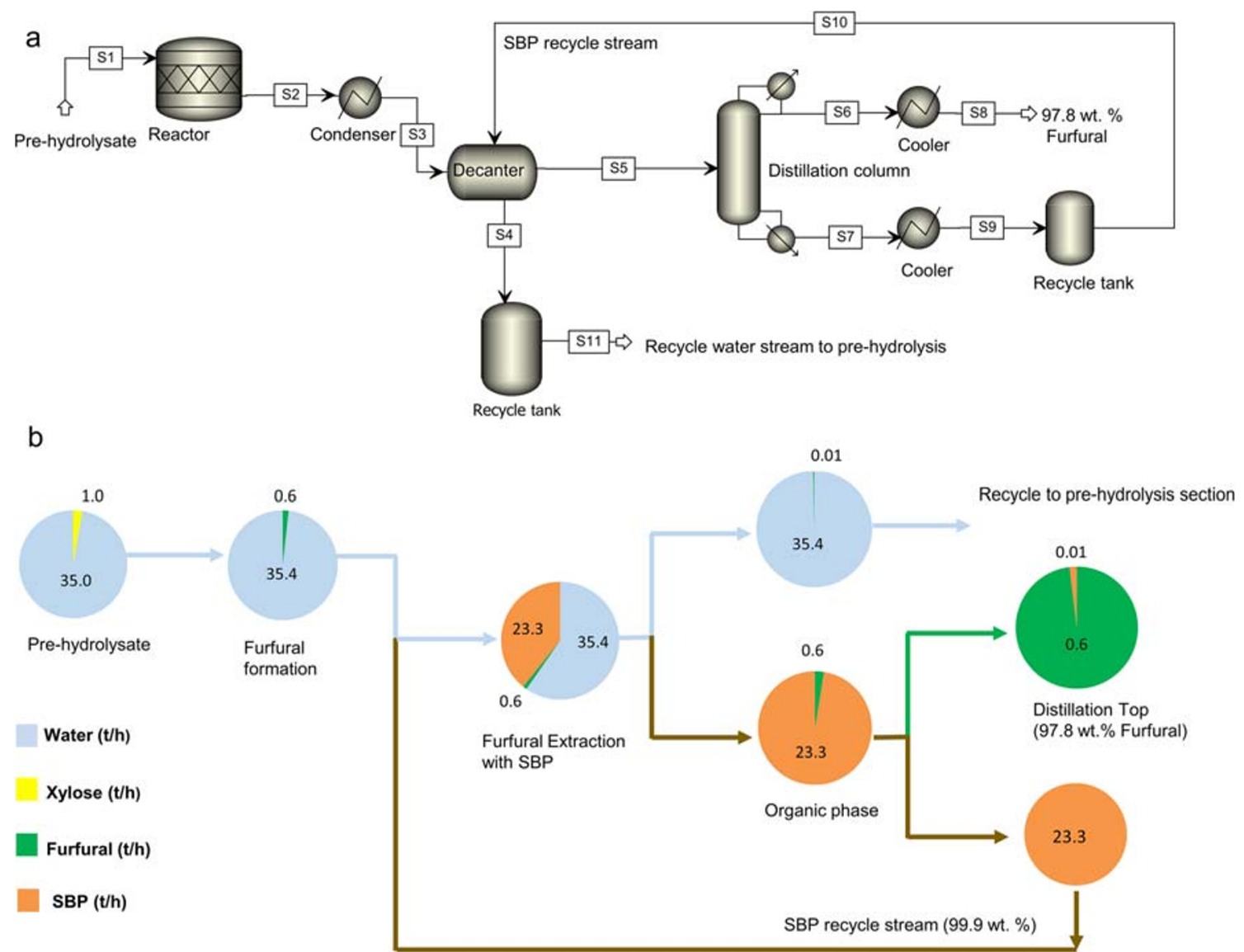

Fig. 4 a Process flow diagram for the production of furfural from birch wood pre-hydrolysate liquor, b mass balance for the production of furfural from birch wood pre-hydrolysate ( $5 \mathrm{kt} /$ year). The reagents used

reactions of FUR take place faster. A similar effect can be seen when employing CPME, isophorone, and MTHF [30].

\subsection{Furfural degradation in the biphasic system}

To broaden understanding of the behavior of FUR under the conditions of microwave-assisted reaction in the presence of SBP, it is indispensable to understand its degradation rate. The FUR degradation experiments were determined employing SBP at the reaction temperatures of 170,190 , and $210^{\circ} \mathrm{C}$ in an auto-catalyzed system. The experimental data exhibiting

Table 2 Process energy balance and utility requirements

\begin{tabular}{lr}
\hline Energy balance & \\
Total heating duty (MW) & 2.7 \\
Total cooling duty (MW) & 26.9 \\
Utility requirements & \\
Cooling water $(\mathrm{t} / \mathrm{h})$ & 551 \\
Steam $(\mathrm{kg} / \mathrm{h})$ & 5638 \\
Electricity $(\mathrm{kW})$ & 422 \\
\hline
\end{tabular}

are given a unique color and the proportion of reagents is displayed using a pie chart. Flow of streams is indicated with the color of the major component the residual fractions of FUR encountered in the aqueous and organic phases at different reaction times are displayed in Fig. A4 (in the Supplementary Information). The figure illustrates the effect of the reaction temperature and time when employing 1:1 aqueous-to-SBP phase ratio on the degradation rate of FUR. The results demonstrate a clear dependency of FUR degradation on the temperature and time, as it can be noticed that when rising the reaction temperature and time, the FUR degradation advances. The highest degree of degradation, $28 \%$, was detected at $210{ }^{\circ} \mathrm{C}$ after $3 \mathrm{~h}$. In a similar manner, published papers have presented likewise data in monophasic systems [36, 45, 46]. Similarly, data published recently when employing isophorone as organic solvent in biphasic systems described a similar effect on FUR formation [30]. Contrastingly, when employing 2-methyltetrahydrofuran (2-MTHF) and cyclopentyl methyl ether (CPME) as organic solvents for biphasic reactions, FUR yields reached $71 \%$ and $78 \%$, respectively. Besides, a lower FUR degradation degree (12\%) was reported under similar conditions when using CPME. This could be due to reactions happening between FUR and unsaturated hydrocarbons via condensation, e.g., SBP and isophorone. Markevich et al. [47] reported the 
Table 3 Estimation of fixed capital and total investment

\begin{tabular}{lr}
\hline Component & M€ \\
\hline Delivered equipment cost & 2.34 \\
Total direct cost & 7.06 \\
Total indirect cost & 2.08 \\
OSBL & 1.41 \\
Contingency & 2.29 \\
Fixed capital investment & 12.84 \\
Working capital & 1.28 \\
Total investment & 14.12 \\
Fixed costs & 2.56 \\
Raw materials and utilities & 4.21 \\
General expenses & 0.46 \\
Annual operating cost & 7.23 \\
\hline
\end{tabular}

reactivity of double bonds in compounds with functional groups; especially, they noted that FUR could be as reactive as acceptor of dimethylcyanomethyl radicals.

\subsection{Auto-catalyzed dehydration of birch hydrolysate}

Hydrothermal reactions of birch hydrolysate were assessed. In addition to xylose and arabinose, birch hydrolysate contains unhydrolyzed xylose and arabinose polymers (arabinoxylan). The presence of both mono-xylose and oligo-xylan has been noted in earlier studies $[48,49]$. Figure 2 shows the FUR yield, pentose (xylose and arabinose) conversion, and selectivity to FUR under various reaction times (between 10 and $180 \mathrm{~min}$ ) at temperatures of 170,190 , and $210^{\circ} \mathrm{C}$. As it can be seen in Fig. 2b, FUR yield and pentose conversion are significantly influenced by the reaction time and temperature, which is in accordance with previous reports on this field $[12,16,17,43$, $50,51]$.

As observed in Fig. 2a, after the first $0.5 \mathrm{~h}$ of the hydrothermal reaction the FUR yield was increased by a factor of four by raising the reaction temperature from 170 to $190{ }^{\circ} \mathrm{C}$.
The largest FUR yield (46\%) was obtained at $190{ }^{\circ} \mathrm{C}$ in $1 \mathrm{~h}$. At temperatures of 170,190 , and $210^{\circ} \mathrm{C}$, the highest selectivity to FUR (Fig. 2c) was $65 \%, 51 \%$, and $43 \%$, respectively. Reaction temperature has also an effect on selectivity to FUR under these conditions. It can be observed that selectivity to FUR at the lowest temperature studied $\left(170{ }^{\circ} \mathrm{C}\right)$ displays the highest value in the present system.

In a work published recently, when using a xylose solution (28 $\mathrm{g} \mathrm{l}^{-1}$ ) under auto-catalyzed conditions FUR yield increased significantly when increasing the reaction temperature from 190 to $210{ }^{\circ} \mathrm{C}$. Contrastingly, when birch hydrolysate liquor is used and dehydrated under auto-catalyzed conditions at $210^{\circ} \mathrm{C}$ FUR yield does not surpass the FUR yield obtained at $190{ }^{\circ} \mathrm{C}$. Under high reaction temperatures $\left(210^{\circ} \mathrm{C}\right)$, it is possible that the reaction takes place faster. Hence, FUR is prone to decompose in a shorter reaction time at high temperatures via condensation (reactions between FUR and intermediates, i.e., pentose and hexose isomers) or resinification (reactions between FUR molecules).

When using birch hydrolysate liquor $(3 \mathrm{ml})$ at $190{ }^{\circ} \mathrm{C}$ in $60 \mathrm{~min}, 5.3 \mathrm{mg}$ of humins were formed in the auto-catalyzed system (Fig. A5 in the Supplementary Information). These insoluble polymers can be valorized as recently published literature demonstrates $[52,53]$. High-value applications of humins include $\mathrm{CO}_{2}$ sequestration, development of catalysts, and soil improvement. The formed humins were analyzed using $\mathrm{N}_{2}$-physisorption, and the sample displays a low surface area of $4 \mathrm{~m}^{2} \mathrm{~g}^{-1}$ (Table A2 in the Supplementary Information).

\subsection{Furfural formation from birch hydrolysate in the biphasic system}

The formation of FUR from birch hydrolysate was investigate under optimized conditions for the dehydration of pentoses as it was determined in the previous sections $\left(190{ }^{\circ} \mathrm{C}, 1: 1\right.$ aqueous-to-SBP phase ratio (by volume), under microwave irradiation). The initial composition of

Fig. 5 Contribution of individual equipment to the total direct cost (TDC)

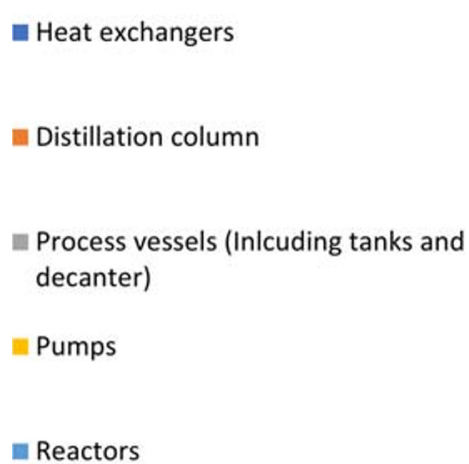

Reactors

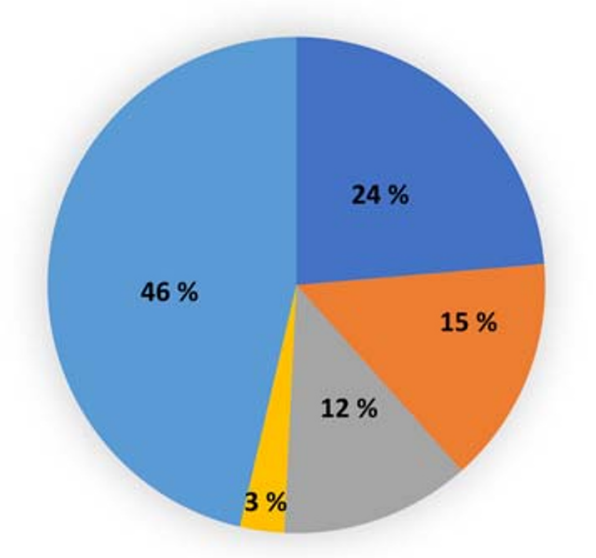


Table 4 Effect of minimum selling price (MSP), total investment (CAPEX), and operating cost (OPEX) for two production capacities (PC)

\begin{tabular}{lcll}
\hline PC (t/year) & OPEX (M€/year) & CAPEX $(\mathrm{M} €)$ & MSP $(€ / \mathrm{kg})$ \\
\hline 5000 & 7.23 & 14.12 & 1.62 \\
10,000 & 13.86 & 21.41 & 1.57 \\
\hline
\end{tabular}

the birch hydrolysate is given in Table A1 (in the Supplementary Information).

The highest FUR yield $(54 \%)$ was reached at $190{ }^{\circ} \mathrm{C}$ in $3 \mathrm{~h}$ using an aqueous-to-SBP phase ratio of 1:1 (by volume) under complete pentose conversion (Fig. $3 \mathrm{a}$ and $\mathrm{b}$ ). Pentose conversion (Fig. 3b) increased from 80 to $94 \%$ when increasing reaction time from 0.5 to $1 \mathrm{~h}$ at $190{ }^{\circ} \mathrm{C}$.

Under similar conditions, $3 \mathrm{~h}$ at $190{ }^{\circ} \mathrm{C}$ with an aqueous-to-CPME phase ratio of $1: 1(\mathrm{v} / \mathrm{v})$, a recent published article reported a FUR yield of $68 \%$ using a birch hydrolysate liquor containing similar xylo-oligosaccharide concentration [30]. This high yield was reached due to the absence of degradation reactions between FUR and CPME.

\subsection{Process simulation}

Process simulation model was developed in Aspen Plus ${ }^{\circledR}$ v8.8 (Aspen Technology, Inc., USA) by using the universal quasichemical (UNIQUAC) thermodynamic method and is shown in Fig. 4.

The pre-hydrolysate stream (S1) from the bio-refinery after lignin separation consisting mostly of xylose (64\% xylooligosaccharides and 36\% monomeric xylose) and water is introduced at $25^{\circ} \mathrm{C}$ into agitated reactors ( 3 reactors in parallel) operating at temperature of $190{ }^{\circ} \mathrm{C}$ and 12.1 bar of pressure with a residence time of $3 \mathrm{~h}$. The stoichiometric reactor model (RSTOIC) available in Aspen Plus is used to simulate the auto-catalyzed reaction of xylose to yield FUR. The outlet stream from the reactor is in vapor phase and is condensed using 2 condensers in parallel. The resulting liquid stream at $98{ }^{\circ} \mathrm{C}$ is then sent to a decanter for separation of the organic and aqueous phases using 2-sec-butylphenol (SBP). A separator block is utilized to model the phase separation in the decanter with a block split fraction of 0.972 for FUR in the organic phase. The aqueous phase pre-dominantly consisting of water ( $99 \mathrm{wt} \%)$ is separated and can be reused in the biorefinery for pre-hydrolysis.

The organic phase consisting of FUR and SBP is introduced into a distillation column operating with 20 ideal stages at atmospheric pressure and a reflux ratio of 1 . The RADFRAC rigorous distillation column in Aspen Plus is used to model the distillation process. A $97.8 \mathrm{wt} \%$ FUR is recovered in the top fraction at $161{ }^{\circ} \mathrm{C}$ and the bottom fraction consisting of pure SBP is recycled back for reuse in the decanter for phase separation. The process flow diagram and mass balance are shown in Fig. 4 .

The energy balance and utility requirements are shown in Table 2. The total heating duty indicates the total energy supplied for the heating of process streams and the total cooling duty indicates the total energy removed by cooling. The process includes the use of utilities such as high-pressure steam for the reboiler, cooling water for heat exchangers, and electricity for pumps. It is assumed that the cooling water is recirculated to a cooling tower for reuse in the process.

\subsection{Process economics}

The total investment cost for a plant with a FUR production capacity of $5 \mathrm{kt} /$ year is found to be $14.12 \mathrm{M} €$ (Table 3). The contribution of individual process equipment to the total direct cost (TDC) is shown in Fig. 5. The reactor units are the most expensive accounting for $46 \%$ of the TDC followed by heat exchangers and distillation column which contribute to $24 \%$ and $15 \%$ of the TDC
Fig. 6 NPV plotted as a function of the project lifetime

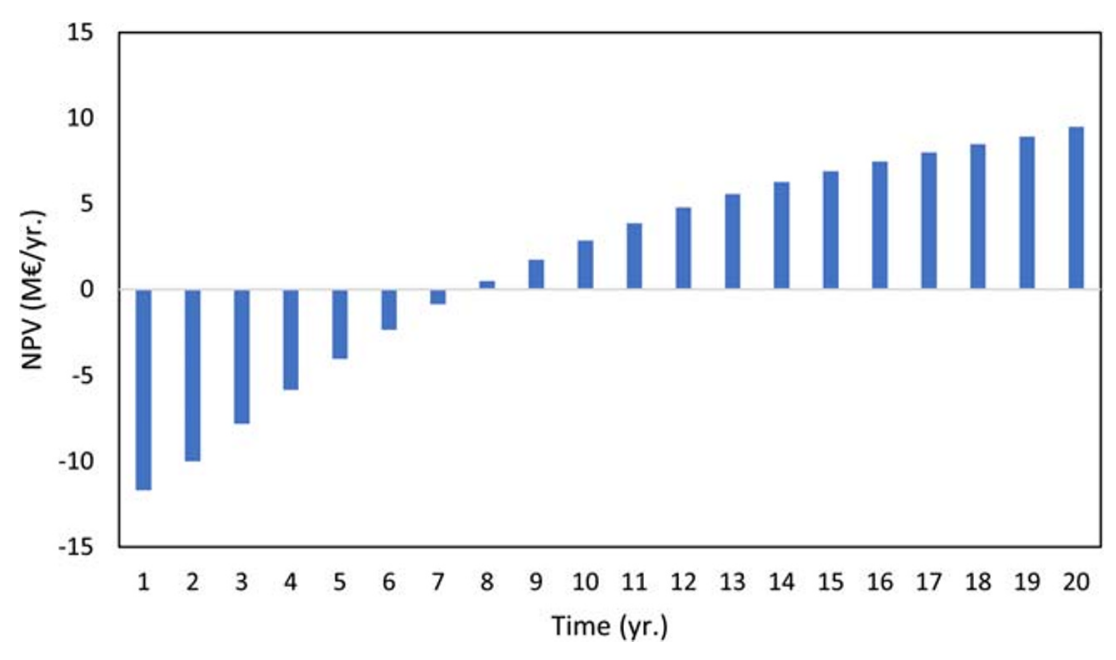


Fig. 7 Sensitivity analysis for evaluating influence of various economic factors on the MSP of furfural. The base values of the economic factors: discount rate $=$ $10 \%$; project lifetime $=20$ years; OPEX = 7.23 M€/year; taxation rate $=20 \%$ and fixed capital investment $=12.84 \mathrm{M} €$

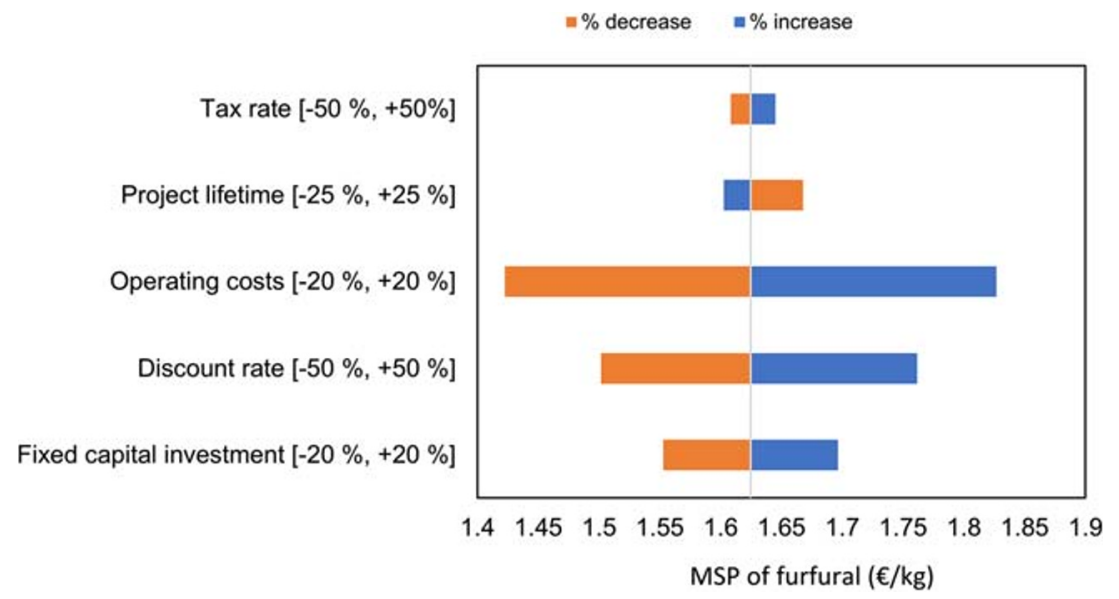

respectively. The annual operating cost consists of fixed costs, variable costs, and general expenses, and is calculated as 7.23 M€. The revenue for the process comes mainly from selling FUR and additional revenue from high-pressure steam condensate that is sold as district heat.

Bbosa and Brown [54] recently completed a technoeconomic analysis of a corn stover-ethanol bio-refinery concept where they set a market price of FUR of $933 € / \mathrm{t}$. Currently, the prices available in Alibaba are in a range from 910 to $1630 € / \mathrm{t}[55]$. $^{2}$ Dalvand et al. [56] determined the market potential of FUR and its derivatives in a recent study. They identified a set of six FUR derivatives to determine the best combination of FUR derivatives and what proportion of FUR should be converted into each derivative. The authors reported a FUR market price of $1359 € / t$. A recent technoeconomic evaluation of bioethanol and FUR coproduction is where they reported a price of $2.37 € /$ gallon and $1540 € / \mathrm{t}$, respectively [57]. These two chemical compounds were produced from corn stover via biochemical and thermochemical routes. Olcay et al. [58] used aqueous phase processing to produce furfural as one of the products from biomass and reported a FUR MSP of $1.53 € / \mathrm{kg}$. MSP, reported in this paper, is quite close to price reported in literature and the existing market price of petrochemical based furfural. The minimum selling price of FUR is calculated at NPV equal to zero with a discount rate of $10 \%$ and is found to be $1.62 € / \mathrm{kg}$ with the payback period being 8.9 years. However, when the FUR selling price is increased to $1.93 € / \mathrm{kg}$, the payback period is 5 years with an NPV of 9.5 M€ at the end of the project lifetime as shown in Fig. 6. The internal rate of return is determined by adjusting the discount rate until the NPV at the end of year 20 is equal to zero and is calculated as $20.7 \%$. The equations used for the calculation of NPV and payback period are given in the Supplementary Information.

${ }^{2}$ Original prices reported in USD were converted to EU with a conversion rate of 1 USD $=0.90612 €$ on September 10, 2019.
The effect of production capacity on the MSP of FUR, total investment, and annual operating cost is shown in Table 4. When the production capacity is doubled, it is observed that there is an increase in the total investment and operating costs and at the same time, the MSP of FUR drops to $1.57 € / \mathrm{kg}$. Tables A3 and A4 (in the Supplementary Information) show the raw materials, utility prices, and cost factors, respectively.

\subsection{Sensitivity analysis}

A sensitivity analysis is carried out to evaluate the effect of various economic factors on the minimum selling price of FUR as shown in Fig. 7. It was observed that annual operating cost, discount rate, and total investment had the biggest impact on the MSP. For instance, when the operating costs and the fixed capital investment increased by $20 \%$, there was an increase of $11.1 \%$ and $4.2 \%$ in MSP respectively. Similarly, when the discount rate was increased by $50 \%$, the MSP increased by $7.8 \%$. Variation in the taxation rate and project lifetime had comparatively smaller influence on the MSP (Fig. 7).

\section{Conclusions}

The conversion of xylose and the resulting furfural yield were studied under well-controlled conditions in a biphasic system with a water-immiscible organic solvent using a model compound, xylose solution, and subsequently birch hydrolysate liquor.

In this process, 2-sec-butylphenol was used as the organic extracting reagent for furfural formed in the reaction. The most favorable organic-to-aqueous ratio in the extraction process was 1:1 (v/v). The highest furfural yield obtained, when using a xylose solution, was $59 \%$ in a two-phase system. When using birch hydrolysate liquor in this biphasic system, 
a furfural yield of $54 \%$ is obtained at $190{ }^{\circ} \mathrm{C}$ in $3 \mathrm{~h}$ under autocatalyzed conditions.

Based on the techno-economic analysis, the minimum selling price of furfural is found to be $1.62 € / \mathrm{kg}$ for a plant operating with a production capacity of $5 \mathrm{kt} / \mathrm{year}$. With a furfural selling price of $1.93 € / \mathrm{kg}$, the payback period is calculated as 5 years resulting in a positive net present value of $9.5 \mathrm{M} €$ at the end of the project lifetime and an internal rate of return of $20.7 \%$. The sensitivity analysis indicated that the annual operating cost, discount rate, and total investment have the largest impact on the minimum selling price of furfural.

Acknowledgments This research has been done in collaboration with Stora Enso. The authors are also grateful for the support of the staff at the Department of Bioproducts and Biosystems, especially to Rita Hatakka and the Department of Chemical and Metallurgical Engineering at Aalto University. This work made use of Aalto University Bioeconomy Facilities.

Funding information Open access funding provided by Aalto University. This study is funded and supported by the Erasmus Mundus Joint Doctoral Programme SELECT+. GGM was supported also by CONACyT-SENER-Sustainable Energy 2016 (the Mexican National Council of Science and Technology-Secretariat of Energy-Sustainable Energy 2016). JL is a Serra Húnter Fellow and is grateful to ICREA Academia program and grant GC 2017 SGR 128.

Open Access This article is licensed under a Creative Commons Attribution 4.0 International License, which permits use, sharing, adaptation, distribution and reproduction in any medium or format, as long as you give appropriate credit to the original author(s) and the source, provide a link to the Creative Commons licence, and indicate if changes were made. The images or other third party material in this article are included in the article's Creative Commons licence, unless indicated otherwise in a credit line to the material. If material is not included in the article's Creative Commons licence and your intended use is not permitted by statutory regulation or exceeds the permitted use, you will need to obtain permission directly from the copyright holder. To view a copy of this licence, visit http://creativecommons.org/licenses/by/4.0/.

\section{References}

1. Mustalahti I (2018) The responsive bioeconomy: the need for inclusion of citizens and environmental capability in the forest based bioeconomy. J Clean Prod 172:3781-3790

2. Ministry of Employment and Economy. (2014) The Finnish bioeconomy strategy: sustainable growth from bioeconomy

3. Lê HQ. Wood biorefinery concept based on $\gamma$-valerolactone/water fractionation 2018: pp 61

4. Rodriguez-Chiang L, Vanhatalo K, Llorca J, Dahl O (2017) New alternative energy pathway for chemical pulp mills: from traditional fibers to methane production. Bioresour Technol 235:265-273

5. Hashmi SF, Meriö-Talvio H, Hakonen KJ, Ruuttunen K, Sixta H (2017) Hydrothermolysis of organosolv lignin for the production of bio-oil rich in monoaromatic phenolic compounds. Fuel Process Technol 168:74-83

6. Gómez Millán G, Hellsten S, Llorca J, Luque R, Sixta H, Balu AM (2019) Recent advances in the catalytic production of platform chemicals from holocellulosic biomass. ChemCatChem 11:2022 2042
7. Zeitsch KJ (2000). 1. Introduction. In: Zeitsch KJ, editor. The chemistry and technology of furfural and its many by-products: Elsevier, p. 1-2

8. Talvitie H and P. Pitkänen. (2014) Cellunolix ${ }^{\circledR}$ ethanol plant to be built in Finland

9. CCM. (2016) CCM: China's market price of furfural bounces back in April

10. Bhisey R. (2019) Furfural market to reach US\$ 672.58 Mn by 2026; rise in demand for furfuryl alcohol to drive market: transparency market research. https://markets.businessinsider.com/news/stocks/ furfural-market-to-reach-us-672-58-mn-by-2026-rise-in-demandfor-furfuryl-alcohol-to-drive-market-transparency-marketresearch-1028137958. Accessed 30.092019

11. Grand View Research. (2015) Furfural market analysis by application (furfuryl alcohol, solvent) and segment forecasts to 2020

12. Gómez Millán G, El Assal Z, Nieminen K, Hellsten S, Llorca J, Sixta H (2018) Fast furfural formation from xylose using solid acid catalysts assisted by a microwave reactor. Fuel Process Technol 182:56-67

13. Peleteiro S, Rivas S, Alonso JL, Santos V, Parajó JC (2016) Furfural production using ionic liquids: a review. Bioresour Technol 202: 181-191

14. Yemiș O, Mazza G (2011) Acid-catalyzed conversion of xylose, xylan and straw into furfural by microwave-assisted reaction. Bioresour Technol 102:7371-7378

15. Lamminpää K, Ahola J, Tanskanen J (2015) Acid-catalysed xylose dehydration into furfural in the presence of kraft lignin. Bioresour Technol 177:94-101

16. Kootstra AMJ, Mosier NS, Scott EL, Beeftink HH, Sanders JPM (2009) Differential effects of mineral and organic acids on the kinetics of arabinose degradation under lignocellulose pretreatment conditions. Biochem Eng J 43:92-97

17. Hongsiri W, Danon B, de Jong W (2015) The effects of combined catalysis of oxalic acid and seawater on the kinetics of xylose and arabinose dehydration to furfural. Int J Energy Environ Eng 6:2130

18. Lin L, Ma S, Li P, Zhu T, Chang H (2015) Mutual solubilities for the water-2-sec-butylphenol system and partition coefficients for furfural and formic acid in the water-2-sec-butylphenol system. J Chem Eng Data 60:1926-1933

19. Azadi P, Carrasquillo-Flores R, Pagan-Torres Y, Gurbuz EI, Farnood R, Dumesic JA (2012) Catalytic conversion of biomass using solvents derived from lignin. Green Chem 14:1573-1576

20. Gürbüz EI, Wettstein SG, Dumesic JA (2012) Conversion of hemicellulose to furfural and levulinic acid using biphasic reactors with alkylphenol solvents. ChemSusChem 5:383-387

21. Romo JE, Bollar NV, Zimmermann CJ, Wettstein SG (2018) Conversion of sugars and biomass to furans using heterogeneous catalysts in biphasic solvent systems. ChemCatChem 10:48054816

22. Argyle DM, Bartholomew HC (2015) Heterogeneous catalyst deactivation and regeneration: a review. Catalysts 5

23. Trimble F, Dunlop AP (1940) Recovery of furfural from aqueous solutions. Ind Eng Chem Anal Ed 12:721-722

24. Zhang J, Zhuang J, Lin L, Liu S, Zhang Z (2012) Conversion of Dxylose into furfural with mesoporous molecular sieve MCM-41 as catalyst and butanol as the extraction phase. Biomass Bioenergy 39: 73-77

25. Gómez Millán G, Phiri J, Mäkelä M, Maloney T, Balu AM, Pineda A, et al. (2019) Furfural production in a biphasic system using a carbonaceous solid acid catalyst. Appl Catal, A

26. Le Guenic S, Gergela D, Ceballos C, Delbecq F, Len C (2016) Furfural production from D-xylose and xylan by using stable Nafion $\mathrm{NR} 50$ and $\mathrm{NaCl}$ in a microwave-assisted biphasic reaction. Molecules 21:1102 
27. Campos Molina MJ, Mariscal R, Ojeda M, López GM (2012) Cyclopentyl methyl ether: a green co-solvent for the selective dehydration of lignocellulosic pentoses to furfural. Bioresour Technol 126:321-327

28. Mittal A, Black SK, Vinzant TB, O'Brien M, Tucker MP, Johnson DK (2017) Production of furfural from process-relevant biomassderived pentoses in a biphasic reaction system. ACS Sustainable Chem Eng

29. Weingarten R, Cho J, Conner J, Curtis W, Huber GW (2010) Kinetics of furfural production by dehydration of xylose in a biphasic reactor with microwave heating. Green Chem 12:14231429

30. Gómez Millán G, Hellsten S, King AWT, Pokki J, Llorca J, Sixta H (2019) A comparative study of water-immiscible organic solvents in the production of furfural from xylose and birch hydrolysate. $\mathrm{J}$ Ind Eng Chem 72:354-363

31. vom Stein T, Grande PM, Kayser H, Sibilla F, Leitner W, Dominguez DM (2011) From biomass to feedstock: one-step fractionation of lignocellulose components by the selective organic acid-catalyzed depolymerization of hemicellulose in a biphasic system. Green Chem 13:1772-1777

32. Sheldon RA (2014) Green and sustainable manufacture of chemicals from biomass: state of the art. Green Chem 16:950-963

33. Merck. Synergy® Water Purification Systems 2012: 1-5

34. Sluiter A, Hames B, Ruiz R, Scarlata C, Sluiter J, Templeton D (2008) Determination of sugars, byproducts, and degradation products in liquid fraction process samples. Technical Report NREL/TP-510-42623

35. Sairanen E, Vilonen K, Karinen R, Lehtonen J (2013) Functionalized activated carbon catalysts in xylose dehydration. Top Catal 56:512-521

36. Lamminpää K, Ahola J, Tanskanen J (2014) Kinetics of furfural destruction in a formic acid medium. RSC Adv 4:60243-60248

37. Lamminpää K, Ahola J, Tanskanen J (2012) Kinetics of xylose dehydration into furfural in formic acid. Ind Eng Chem Res 51: 6297-6303

38. Givry S, Bliard C, Duchiron F (2007) Selective ketopentose analysis in concentrate carbohydrate syrups by HPLC. Carbohydr Res 342:859-864

39. Pirola C, Rossetti I, Ragaini V (2013) Are conversion, selectivity and yield terms unambiguously defined in chemical and chemical engineering technology? La Chimica \& L'Industria 2:136-145

40. Peters, M. S., Timmerhaus, K. D. and West, R. E. (2003) Plant design and economics for chemical engineers 5 th edition, McGraw-Hill

41. Sinnott RK, Coulson JM, Richardson JF (2005) Coulson \& Richardson's chemical engineering. Vol. 6, Vol. 6, Elsevier Butterworth-Heinemann

42. Verbeeck K, Buelens L, Galvita V, Marin G, Van Geem K, Rabaey K (2018) Upgrading the value of anaerobic digestion via chemical production from grid injected biomethane. Energy Environ Sci 11: $1788-1802$

43. NCBI homepage U.S. National Library of Medicine National Center for Biotechnology Information. PubChem: 2-SecButylphenol (Compound). https://pubchem.ncbi.nlm.nih.gov/ compound/2-sec-Butylphenol\#section=Flash-Point. Accessed 5. 92019
44. Danon B, Hongsiri W, van der Aa L, de Jong W (2014) Kinetic study on homogeneously catalyzed xylose dehydration to furfural in the presence of arabinose and glucose. Biomass Bioenergy 66: 364-370

45. Marcotullio G, de Jong W, Tavares Cardoso MA, Verkooijen AHM (2009) Bioenergy II: furfural destruction kinetics during Sulphuric acid-catalyzed production from biomass. Int $\mathrm{J}$ Chem React Eng 7(1):A67

46. Danon B, van der Aa L, de Jong W (2013) Furfural degradation in a dilute acidic and saline solution in the presence of glucose. Carbohydr Res 375:145-152

47. Markevich IN, Borisova GS, Glebova NN, Sharaev OK, Ostrovskaya IY, Gol'berg AI (1989) Relative reactivities of double bonds in compounds with functional groups towards the dimethylcyanomethyl radical. Bulletin of the Academy of Sciences of the USSR, Division of chemical science 38:789-792

48. Saeed A, Jahan MS, Li H, Liu Z, Ni Y, van Heiningen A (2012) Mass balances of components dissolved in the pre-hydrolysis liquor of kraft-based dissolving pulp production process from Canadian hardwoods. Biomass Bioenergy 39:14-19

49. Tunc MS, van Heiningen Adriaan R.P. Hydrothermal dissolution of mixed southern hardwoods. Holzforschung 2008; 62: 539

50. Sahu R, Dhepe PL (2012) A one-pot method for the selective conversion of hemicellulose from crop waste into C5 sugars and furfural by using solid acid catalysts. ChemSusChem 5:751-761

51. Chen XJ, Liu XQ, Xu FL, Bai XP (2012) Degradation kinetics of xylose and arabinose in subcritical water in unitary and binary system. Adv Mater Res 450-451:710-714

52. van Zandvoort I. Towards the valorization of humin by-products: characterization, solubilization and catalysis 2015

53. Hoang TMC, Lefferts L, Seshan K (2013) Valorization of huminbased byproducts from biomass processing - a route to sustainable hydrogen. ChemSusChem 6:1651-1658

54. Bbosa D, Mba-Wright M, Brown RC (2018) More than ethanol: a techno-economic analysis of a corn stover-ethanol biorefinery integrated with a hydrothermal liquefaction process to convert lignin into biochemicals. Biofuels Bioprod Biorefin 12:497-509

55. Alibaba. (2019) Factory wholesale low price furfural. https://www. alibaba.com/product-detail/Factory-wholesale-low-price-furfural $1264137027 . \mathrm{html}$ ?spm=a2700.7724857.normalList.63. 73cf6033C7RiNK. Accessed 9/102019

56. Dalvand K, Rubin J, Gunukula S, Clayton Wheeler M, Hunt G (2018) Economics of biofuels: market potential of furfural and its derivatives. Biomass Bioenergy 115:56-63

57. Hossain MS, Theodoropoulos C, Yousuf A (2019) Technoeconomic evaluation of heat integrated second generation bioethanol and furfural coproduction. Biochem Eng J 144:89103

58. Olcay H, Malina R, Upadhye AA, Hileman JI, Huber GW, Barrett SRH (2018) Techno-economic and environmental evaluation of producing chemicals and drop-in aviation biofuels via aqueous phase processing. Energy Environ Sci

Publisher's Note Springer Nature remains neutral with regard to jurisdictional claims in published maps and institutional affiliations. 